\title{
A SEGMENTAÇÃO DO ENOTURISTA: O CASO PORTUGUÊS ${ }^{1}$
}

SEGMENTATION OF WINE TOURISTS: THE CASE OF PORTUGAL

LA SEGMENTACIÓN DEL ENOTURISTA: EL CASO PORTUGUÉS

\section{Edgar Teles Marques Salgado Lameiras \\ Instituto Politécnico de Leiria}

Docente da Escola Superior de Educação e Ciências Socias do Instituto

Politécnico de Leiria

Doutor em Turismo pela Faculdade de Economia da Universidade do Algarve, Portugal Leiria, Portugal edgar.lameiras@ipleiria.pt

Julio da Costa Mendes

Universidade do Algarve

Docente da Universidade do Algarve Doutor em Gestão pela Universidade do Algarve Faro, Portugal jmendes@ualg.pt

\section{Patrícia Susana Lopes Guerrilha dos Santos Pinto}

Universidade do Algarve

Docente da Faculdade de Economia da Universidade do Algarve Doutora em Métodos Quantitativos aplicados à Economia e à Gestão na especialidade de Estatística pela Universidade do Algarve

Faro, Portugal

pvalle@ualg.pt

1 Este trabalho é financiado por fundos nacionais fornecidos pela FCT-Fundação para a Ciência e Tecnologia através do projeto UID/SOC/04020/2013. 


\title{
João Albino Matos da Silva
}

Universidade do Algarve

Docente da Faculdade de Economia da Universidade do Algarve Doutor em Economia pela Universidade Técnica de Lisboa Algarve, Portugal jsilva@ualg.pt

\author{
Data de Submissão: 12/05/2016 \\ Data de Aprovação: 23/06/2016
}

RESUMO: $O$ enoturismo adquire importância crescente para as regiões vitivinícolas, como setor que potencia o crescimento económico e o emprego. Contudo, o enoturismo permanece pouco desenvolvido e uma das causas apontadas consiste na falta de investigação sobre o visitante que se desloca às empresas produtoras de vinho. $O$ presente trabalho tem como principais objetivos a determinação do perfil demográfico e psicográfico dos visitantes que se deslocam às quintas, adegas e caves e a segmentação dos enoturistas em Portugal. Para alcançar os objetivos indicados, aplicou-se um questionário aos turistas que se deslocavam às quintas, adegas e caves, das 12 rotas de vinho existentes em Portugal. Os dados foram sujeitos a testes paramétricos e a técnicas estatísticas multivariadas, de modo a obterem-se diferentes clusters. Obtiveram-se quatro segmentos de enoturistas, que foram designados por: o turista apaixonado pelo vinho, o turista com curiosidade pelo vinho, o turista interessado pelo vinho e o turista indiferente. As conclusões indicam que o aumento do conhecimento sobre enoturistas e suas motivações para visitarem uma região permite melhorar a satisfação e a interação com eles, apoiando estratégias de marketing, de modo a reforçar a sua motivação e o apelo das empresas vinícolas.

PALAVRAS-CHAVE: Enoturista, motivações, segmentação.

ABSTRACT: Wine tourism is growing in importance for the wine-growing regions, as a sector that promotes economic growth and employment. However, this tourism segment is still underdeveloped. One of the reasons cited for this is a lack of research on visitors to wineries. This work therefore seeks to determine the demographic and psychographic profile to vineyards, wineries and wine cellars, and the segmentation of these tourists in Portugal. To achieve the proposed objectives, a survey was applied to tourists who visited vineyards, wineries and wine cellars that are part of the twelve wine routes located in different regions of Portugal. The data were subjected to parametric tests and multivariate statistical analysis, to obtain different clusters. Four wine tourism segments were identified: the tourist who is a wine connoisseur; the tourist who is curious about wines; the tourist who is slightly interested in wines; and the tourist who is indifferent about wines. The conclusions indicate that increasing knowledge about wine tourists and their aims and motivations when visiting a region can lead to improved satisfaction of the tourists and greater interaction with them, supporting marketing strategies, in order to reinforce their motivation and the appeal of wine-growing companies.

KEYWORDS: Wine tourism, enoturist, routes, motivations, segmentation. 
RESUMEN: El enoturismo adquiere creciente importancia para las regiones vitivinícolas como sector que potencia el crecimiento económico y el empleo. Sin embargo, el enoturismo permanece poco desarrollado y una de las causas apuntadas consiste en la falta de estudios sobre el visitante que se traslada hasta las empresas productoras de vino. El presente trabajo tiene como principales objetivos la determinación del perfil demográfico y psicográfico de los visitantes que se trasladan hasta las quintas, bodegas y sótanos y la segmentación de los enoturistas en Portugal. Para alcanzar los objetivos indicados se aplicó un cuestionario a los turistas que se trasladaban a las quintas, bodegas y sótanos de las 12 rutas de vino existentes en Portugal. Los datos se sujetaron a testes paramétricos y a técnicas estadísticas multivariadas, de modo que se obtuvieron distintos clusters. Se obtuvieron cuatro segmentos de enoturistas, que fueron designados como: el turista apasionado por el vino, el turista con curiosidad por el vino, el turista interesado en el vino y el turista indiferente. Las conclusiones indican que el aumento del conocimiento sobre los enoturistas y sus motivaciones para visitar una región permite mejorar la satisfacción y la interacción con ellos, apoyando estrategias de marketing para reforzar su motivación y el atractivo de las empresas vinícolas.

PALABRAS CLAVE: Enoturista; Motivaciones; Segmentación.

\section{INTRODUÇÃO}

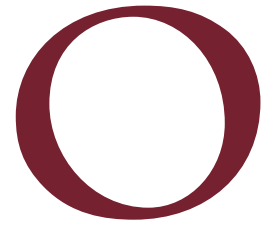

enoturismo ocorre quando a motivação e a decisão de viajar são determinadas principalmente pela atração por um tema particular, neste caso, o vinho (Zamora \& Barril, 2007). Hoje em dia, conhecer o vinho e também as vinhas, as suas histórias, a sua produção e as suas marcas é reflexo de prestígio, o mesmo acontecendo com as visitas às vinhas onde ele é produzido e apreciado por tantos (Lavandoski, VargasSánchez, Pinto \& Silva, 2016). O vinho torna-se então um símbolo de estilo de vida, fortemente ligado aos valores e aos processos pelos quais os indivíduos procuram atingir os seus objetivos, por meio de diferentes modos de expressão, incluindo o consumo de vinho (Bruwer \& Reid, 2002; Pastor, 2006).

O turista atual deseja algo mais personalizado e mais dirigido. Neste contexto, surgiram novos produtos nos quais, entre outros, se inclui o turismo nas regiões da uva e do vinho (Favero \& Rotta Antunes, 2007; Tonini, 2007; Torre, Ferreira \& López-Guzman, 2008; Iglesias \& Navarro, 2014). Muitos dos designados enoturistas não associam a si mesmos a tal designação, cabendo à comunidade científica descrever e caracterizar o enoturista (Charters \& Ali-Knight, 2002). Torna-se, pois, fundamental obter dados relacionados com os gostos, as motivações, a origem e o perfil dos enoturistas, de modo a conseguir-se uma 
segmentação ajustada ao tipo de procura. Muitos trabalhos de investigação têm sido realizados, mas incidindo fundamentalmente na perspetiva da oferta, baseados em entrevistas e inquéritos realizados a produtores e gestores de adegas. Ao invés, investigações na ótica do visitante, ou seja, na perspetiva da procura, têm sido em número substancialmente mais reduzido. Como referem Tassiopoulos, Nuntsu e Haydam (2004), para as adegas permanecerem competitivas, têm de ter em conta as necessidades e as expetativas dos enoturistas. Importa portanto realizar um maior número de estudos nesta ótica, de modo a sensibilizar as adegas para a aplicação e a adaptação dos resultados, orientando-as para a procura, no sentido da rentabilização e otimização dos seus esforços e despesas.

A questão de partida para esta investigação foi a seguinte: "Os turistas que visitam regiões vitivinícolas e as respetivas quintas, caves e adegas, possuem características diferenças que permitem dividi-las em grupos com características semelhantes entre si, mas diferentes em relação a outros grupos?". Neste contexto, o presente estudo pretende determinar as características, as motivações e os comportamentos dos visitantes de caves, adegas e quintas de produção de uva e vinho em Portugal, tendo em vista a obtenção dos diferentes grupos de visitantes e sua caracterização.

Na presente investigação, procedeu-se à aplicação de inquéritos a visitantes que se deslocaram a adegas, quintas e caves, aderentes das 12 rotas do vinho existentes em Portugal, de modo a caraterizar o enoturista e a segmentá-lo. Pretende-se que este estudo possa contribuir de modo significativo para um melhor conhecimento deste tipo específico de consumidor, podendo os seus resultados constituir uma ferramenta dotada de utilidade para as administrações das explorações vitivinícolas.

\section{O SISTEMA DO ENOTURISMO}

O turista possui determinado número de intenções quando se desloca a uma região produtora de vinhos. O local, por um lado, e o turista, com as suas intenções e interesses, por outro lado, são os principais fatores que determinam a oferta e a procura do enoturismo. O consumidor potencial do enoturismo 
ISSN: 1983-7151

possui um conjunto de crenças sobre os atributos que integram a experiência do enoturismo. Esse conjunto de crenças tem origem em diferentes fontes, como por exemplo a experiência passada, a informação que passa de boca em boca e a publicidade. Além de ser necessário compreender quais as crenças que as pessoas têm sobre o enoturismo, é igualmente importante determinar de que modo é que estas crenças são valorizadas pelos consumidores (Ajzen \& Fishbein, 1980). Para se compreenderem as intenções do turista que visita uma região produtora de vinhos, será sempre necessário saber antecipadamente quais são os atributos dessa área (Pike, 2002). Getz e Brown (2006) consideram como principais atributos o apelo do destino, o produto cultural e os principais produtos do vinho. A existência de vinhas e adegas onde o vinho é produzido e armazenado, a oportunidade de comprar vinho e um interesse em dominar os assuntos relacionados com o vinho, assim como a possibilidade de interação social, são outros dos diferentes atributos considerados pelos autores (Dodd \& Bigotte, 1997; Mitchell, Hall \& MacIntosh, 2002).

Pelo lado da oferta, o enoturismo pode ser considerado como o conjunto de todas as atividades associadas à visita a adegas, museus eoutros estabelecimentos ligados ao setor, tendo como principal objetivo o propósito de terem uma experiência relacionada com a temática do vinho, como é o conhecimento dos vinhos e a sua prova, assim como o conhecimento das regiões, instituições e organizações visitadas, incluindo as caves, as adegas, as quintas, os festivais, os eventos, as visitas guiadas, o alojamento, a restauração e os bares, o artesanato, a produção de alimentos, as infraestruturas que suportam um destino e as atividades associadas. Ou seja, pressupõe o contacto direto do turista com as atividades vitivinícolas e com os produtos resultantes destas atividades e com o património paisagístico e arquitetónico relacionado com a cultura e com a produção do vinho (Simões, 2008). A oferta criada faz com que o enoturista pretenda passar por experiências confortáveis e autênticas numa atmosfera emocionante e relaxante. Pretende-se que a autenticidade não seja baseada em objetos, mas em sentimentos das pessoas envolvidas nas atividades (Wang, 1999; Taylor, 2001). A indústria do turismo e a indústria do vinho harmonizam-se originando o compósito do enoturismo que, contextualizado como uma cadeia de valor, torna possível acrescentar valor à fase anterior. Esse valor acrescentado pode ser económico, mas também social, cultural ou ambiental. 


\section{CONCEITO DE ENOTURISTA}

Apesar de a realização de estudos científicos sobre o enoturismo ser de origem recente, encontram-se na literatura alguns trabalhos de relevo no que diz respeito à classificação dos enoturistas relativamente ao seu perfil, não existindo contudo uma opinião unânime do que são os enoturistas. Getz e Brown (2006) atribuem esta discordância, em parte, ao facto de o produto enoturístico ou a experiência enoturística ainda não poderem ser definidos com confiança. No intuito de se compreender melhor o fenómeno do enoturismo, é fundamental definir um perfil do enoturista (Hall et al., 2002a, 2002b). A falta de qualidade de informações disponíveis no mercado confirma que esta é uma área em que é preciso investir. Apesar de tudo, e ao contrário da investigação realizada no respeitante às políticas do turismo de vinho e da economia, a pesquisa em relação aos enoturistas é bem desenvolvida (Goldberg \& Murdy, 2006). Grande parte da investigação recai sobre os enoturistas e as suas relações com questões especiais relativas aos produtos ou aos serviços específicos de vinho e não investigam os enoturistas de um modo geral (Williams \& Kelly, 2001).

As primeiras referências feitas sobre os enoturistas não são as descrições mais lisonjeiras para estes. Por exemplo, Mitchell, Hall e McIntosh (2002) e Mitchell e Hall (2006) consideram que os enoturistas são indivíduos entre os 30 e os 50 anos de idade e encontram-se numa faixa de rendimento de moderada à alta. Vivem perto da região que visitam e são regulares consumiores de vinho e com um conhecimento sobre vinho que se pode considerar de intermédio.

Dois procedimentos são os mais comumente utilizados pela maior parte dos investigadores para analisar os enoturistas como um potencial mercado: um primeiro procedimento, em que os investigadores classificam os enoturistas considerando as suas características demográficas, como a origem, a idade, a educação e a família; ou então um segundo procedimento, em que os autores estabelecem um perfil detalhado das características psicográficas dos enoturistas, como as suas motivações, os seus interesses, 
as suas opiniões, os seus valores, as suas atitudes, as suas crenças ou os seus estilos de vida (Charters \& Ali-Knight, 2002; Mitchell \& Hall, 2006; Johnson \& Bruwer, 2007). Mas os procedimentos não se nuclearizam às características demográficas ou psicográficas. Getz (2000), por exemplo, considera ainda outro critério para classificar o enoturista que tem a ver como a forma como o turista procura a informação, denominado communications. Outros autores aditam ainda o comportamento do enoturista como consumidor de vinho (Williams \& Young, 1999).

Somente em 1995 os académicos começaram a focar no enoturista, embora na maior parte das vezes a recolha tenha sido realizada do lado da oferta, em vez da perspetiva dos consumidores de turismo de vinhos (Mitchell et al., 2002), sendo os estudos normalmente feitos a partir da perceção que os vitivinicultores possuem sobre o indivíduo que visita a sua adega e não com base em qualquer recolha de dados e sua análise com o mínimo de credibilidade científica. Para o produtor, os visitantes ou são "sophisticated drinker", que anseiam por novas informações e a maneira como elas podem ser obtidas, que correspondem a uma baixa percentagem dos visitantes de adegas (variando com a dimensão da adega e a reputação dos seus vinhos); ou em número maior os "casual tourist", que se limitam a olhar, a provar e um pouco mais, ou maioritariamente, a categoria intermédia, que são indivíduos que não têm conhecimento específico sobre o vinho, mas que bebem regulamente vinho e que estão interessados em aprender e por passar por aquela experiência (Charters \& Ali-Knight, 2002).

Os investigadores tentam encontrar um perfil para os enoturistas, ainda que por vezes um perfil muito simples. Surgem deste modo as primeiras descrições com base na idade, no rendimento, na profissão, na escolaridade ou no sexo (Dodd, 1995; Folwell \& Grassel, 1995; Getz, 2000; Treloar, Hall \& Mitchell, 2004, O’Neill \& Charters, 2006). Numa avaliação deste género há que considerar sempre o aspeto da variação cultural, que é demasiado relevante, principalmente quando se comparam enoturistas ou enoturismo entre países da Europa e países do Novo Mundo. Além da estrutura da indústria do vinho ser completamente diferente, por exemplo entre a Europa e o Novo mundo, também o enoturismo, de acordo com as suas regiões produtoras, pode apresentar características completamente diferentes. 


\section{ASPETOS COMPORTAMENTAIS DO ENOTURISTA}

O comportamento do consumidor reflete o conhecimento como uma variável que influencia todas as fases do processo de decisão, particularmente com a pesquisa de informação (Barber, Taylor \& Dodd, 2009). O conhecimento prévio de um produto é o resultado acumulado de três contribuições: (1) a familiaridade (familiarity), (2) a perícia (expertise) e (3) a experiência anterior (past experience). A familiaridade refere-se ao que os consumidores pensam que sabem sobre o produto, isto é o conhecimento subjetivo que os turistas têm sobre o destino (Baloglu, 2001). Resulta de um compósito que está relacionado com o tempo que os indivíduos passam a processar a informação sobre um produto ou sobre um serviço, independentemente do tipo ou conteúdo do comportamento e resulta da percepção sobre um produto/serviço e não obrigatoriamente da experiência real, tendo a ver com as visitas anteriores e ou o número de vezes que visitou esse sítio, mas igualmente com o nível de conhecimento que ele tem, o que pode originar uma imagem favorável ou uma relação de afeto positivo, o que pode aumentar o desejo de viajar (Kerstetter \& Cho, 2004). Os turistas tendem a ganhar familiaridade com o destino por meio da pesquisa de livros, guias, publicidade, artigos de jornais, de revistas e de televisão relacionados e conversando com amigos e familiares.

No enoturismo, o nível de conhecimento sobre o produto vinho é um indicador usado com frequência na investigação (Mitchell \& Hall, 2003). O conhecimento sobre o vinho pode ser adquirido através de diferentes fontes de informação, podendo variar de indivíduo para indivíduo de acordo com o seu envolvimento com o produto vinho. Quantificar aquilo que o enoturista julga que sabe sobre o vinho é algo difícil, já que parte de uma percepção que o enoturista tem sobre si próprio, sobre os seus próprios conhecimentos (Charters \& Ali Knight, 2002). Mais fácil é questionar os proprietários/gestores das adegas sobre as eventuais diferentes categorias que melhor definem os visitantes das adegas. 
Charters e Ali-Knight (2002) consideram que alguns consumidores de vinho se tornam enoturistas apenas para melhorar o seu conhecimento sobre o vinho. Existe uma forte correlação entre o envolvimento e o comportamento de consumo do enoturista (Brown \& Getz, 2005). Mitchell et al. (2002) acrescentam que as pessoas que possuem um alto envolvimento com o vinho viajam mais a regiões vitivinícolas. Hall (1996) foi o primeiro investigador a debruçar-se sobre uma classificação dos enoturistas com base no conhecimento destes sobre o vinho, tendo-os classificado em wine lovers, wine interested e wine courious. Mais tarde Charters e Ali-Knight (2002) acrescentam a esta classificação uma nova categoria ao incluir o connaisseur, cujo grupo é constituído por pessoas que estão interessadas em aprender sobre vinho. Os autores detetam ainda um outro grupo, denominado hanger-on, que são as pessoas que não possuem nenhum interesse aparente sobre o vinho, mas que fazem parte de um grupo que decidiu fazer uma visita.

Dodd (1999), com base numa investigação realizada na Nova Zelândia, considera que os enoturistas podem ser classificados em dois principais grupos relativamente aos seus conhecimentos: "avançado ou especialista" e "básico ou intermédio". Charters e Ali-knight (2002) desenvolveram um estudo, igualmente na nova Zelândia, considerando que os enoturistas se classificam a si mesmo como altamente experientes, com conhecimento intermédio sobre o vinho e com um conhecimento limitado. As pessoas procuram informações sobre um destino enoturístico de forma a reduzir de algum modo o risco percebido e/ou ajudar na sua tomada de decisão (Sparks, 2007). De um modo geral, os turistas planeiam as suas viagens às regiões das uvas com base em informação que recolhem na internet de sites locais (de acordo com a quantidade de websites que existem sobre uma rota ou sobre as adegas dessa região), mas também com base em informação obtida através da família ou de amigos, guias, revistas, publicidade de viagens, suplementos de jornais, folhetos e experiências anteriores (Roberts \& Sparks, 2006; Tassiopoulos \& Haygdam, 2006; Dawson et al., 2011). Muitos autores consideram mesmo o "passa-palavra" de amigos e familiares como de grande importância, ou mesmo a melhor fonte de informação, e um método eficaz de marketing para a indústria do enoturismo, nomeadamente em países como a Austrália ou a NovaZelândia (Brown \& Getz, 2005; Bruwer \& Reily, 2006; Stoddard \& Evans, 2011). 


\section{SEGMENTAÇÃO DO ENOTURISTA}

Com demasiada frequência, muitos donos de adegas e operadores de turismo têm dificuldade em distinguir o nível de interesse e compromisso do turista para com a região deles (Bruwer et al., 2002; Tassiopoulos et al., 2004; Morton \& Houghton, 2008). Tal como Charters e Ali-Knight (2002:312) afirmam, "there is no single, stereotypical 'wine tourist, - nor there is a unilateral definition of him or her".

As empresas têm de saber quem são os seus clientes, quais as razões que os levam a viajar, quais os seus gostos, hábitos, costumes, preferências, origens, perfil e outras caraterísticas, de modo a terem um conhecimento prévio dos viajantes e poderem criar um segmento de mercado que possa ser isolado do mercado global e constituir o destinatário de um plano de estratégias de marketing, diferenciado de acordo com o interesse dos viajantes (Oliveira, 2002). Existem várias bases de segmentação que incluem dados geográficos, demográficos, psicografia, despesa, benefícios, atividades, canais de informação, não havendo, no entanto, consenso relativamente à variável tomada como sendo a ideal (Jang, Morrison \& O'Leary, 2002).

A literatura científica revela diferentes segmentos de enoturistas com base em investigações realizadas em todo o mundo, como os países anglo-saxónicos da Oceânia ou os países europeus. É a partir de 1995 que os investigadores tentam encontrar um perfil para os enoturistas, ainda que por vezes um perfil muito simples. Surgem, deste modo, as primeiras descrições com base na idade, no rendimento, na profissão, na escolaridade ou no sexo (Dodd, 1995; Folwell \& Grassel, 1995; Treloar, Hall \& Mitchell, 2004, O'Neill \& Charters, 2006). Do lado da oferta, realçam-se os estudos realizados por Hall e Macionis (1998) e Corigliano (1996), que apresentam as primeiras propostas de segmentação para o enoturista, recorrendo a caraterísticas psicográficas dos enoturistas. Alebaki e Iakovodou (2010), recorrendo aos aspetos sociodemográficos e às motivações que levavam os turistas a visitar uma adega, segmentam os enoturistas da Macedónia em quatro grupos. Tassiopoulos et al. (2004) realizam um trabalho relevante com base em características psicográficas e demográficas. Com base 
nas emoções de referir, ressaltam-se as investigações realizadas por Galloway, Mitchell, Getz, Crouch e Ong (2008) na Austrália. Os trabalhos realizados por Marzo-Navaro e Pedraja-Iglesias (2009a, 2009b, 2010), na Espanha, tomam em consideração o grau de envolvimento dos enoturistas com o vinho. Apontamse também as investigações realizadas por Chen e Sasias (2014), que se basearam nos valores culturais e estilo de vida de enoturistas em Taiwan. Há, ainda, segmentações com base no seu interesse e conhecimento sobre o vinho. Charters e Ali-Knight (2001), por exemplo, numa pesquisa realizada na Austrália sobre a segmentação dos enoturistas, classificaram os enoturistas em: wine lover, the connoisseur, wine interested, wine novice. Também usando o nível de envolvimento com o produto, Brown, Havitz e Getz (2006) classificam os enoturistas em fastidious epicureans, hedonic aficionados, cautious enthusiasts e functional differentiators. Num estudo com objetivos semelhantes, Marzo Navarro e Pedraja-Iglesias (2009a) classificaram os enoturistas em dois grandes grupos: wine-interested tourists e os curious tourists ou wine novice. Por sua vez, Alebaki e Iakovidou (2010) fizeram um estudo sobre o consumo de vinho na Grécia e concluíram que havia dois grupos: os altamente interessados em vinho e uva e os que têm um interesse limitado ou não têm interesse no vinho.

\section{PROCEDIMENTOS METODOLÓGICOS}

\section{POPULAÇÃO ALVO, AMOSTRA E RECOLHA DOS DADOS}

Não havendo dados sobre a população de enoturistas em Portugal e ainda sendo poucas as rotas e as estruturas enoturísticas que recolhem dados sobre o número de enoturistas que as visitam, premissa fundamental do processo de amostragem, foi opção, para a execução desta investigação, considerar os visitantes que se deslocavam às quintas/adegas e caves que fazem parte de cada uma das 12 rotas de vinho existentes em Portugal (Ghiglione \& Matalon, 2001; Hill \& Hill, 2005). Por tal foi assumido que o universo populacional a considerar seria não só o dos visitantes que se deslocam às quintas, produtoras de uva e vinho; às adegas, que produzem o vinho; e às caves, onde produzem e armazenam o vinho; mas igualmente às casas-mãe das rotas ou às estruturas, que 
desempenham esta função e aos museus do vinho e cooperativas, que integram rotas em Portugal. Foi realizado um questionário com questões essencialmente fechadas, constituído pelas seguintes partes: solicitação da indicação da adega e da rota visitada; planeamento e aspetos comportamentais da organização da visita; aspetos relacionados com a aquisição da informação; aspetos psicográficos, comportamentais e motivacionais; aspetos relativos ao interesse e à satisfação; conhecimento sobre o setor vitivinícola; aspetos sociodemográficos.

Para a aplicação do questionário e na impossibilidade técnica de alcançar os visitantes de mais de 300 aderentes das 12 rotas de vinho em Portugal, solicitaram-se à entidade gestora de cada rota que indicasse, na perceção dela, os aderentes que recebiam ao longo do ano maior número de visitantes. Foi solicitado que indicassem um número entre 5 e 10 aderentes. Foram indicados, no total das 12 rotas do vinho, 97 aderentes. Cada um dos aderentes foi contactado primeiro por e-mail e posteriormente pessoalmente no sentido de promover uma sensibilização para consequente aderência ao projeto de investigação. A cada um dos aderentes indicados foi entregue um cartaz a cores de formato $\mathrm{A} 2$ colado a uma base rígida de polipropileno, com uma estrutura simples que permitia que o cartaz se mantivesse na vertical sem a ajuda de qualquer outro artefacto adicional. O cartaz convidava o visitante (em quatro idiomas; português, francês, inglês e espanhol) a colaborar na investigação, devendo para o efeito deixar as seguintes indicações: nome, data, país de origem e endereço electrónico numas folhas realizadas para o efeito que se encontravam junto ao cartaz.

A recolha das folhas foi feita posteriormente junto de cada aderente. No total foram recebidos 2.024 endereços eletrónicos oriundos de diferentes países, tendo sido enviado para cada indivíduo que deixou o respetivo endereço de e-mail a solicitar o preenchimento de um questionário via on-line, podendo os intencionais respondentes optarem pelo idioma preferido, já que o questionário se encontrava disponível na plataforma LimeSurvey também em 4 idiomas diferentes. No total foram rececionados 2024 endereços eletrónicos oriundos de diferentes países para os quais foi solicitado o preenchimento do questionário. Deste procedimento resultaram 615 questionários respondidos, correspondendo a uma taxa de resposta de 30,28\%. Destes, 410 apresentavam 
menos de $20 \%$ de casos omissos, tendo sido posteriormente considerados na análise de dados.

\section{ANÁLISE DOS DADOS}

Procedeu-se à análise e interpretação dos dados recorrendo a estatísticas descritivas através de software estatístico Stastical Package for Social Sciences (SPSS) na versão 19.0, com vista à organização e apresentação dos dados. Com o fim de identificar os determinantes que motivaram os enoturistas a visitar as quintas selecionadas, o conjunto de itens que integram a escala de motivos dessas visitas foi submetido a uma Análise fatorial exploratória. Foi avaliada a consistência interna e a homogeneidade dos itens que integravam os motivos de visita às quintas/adegas/caves através do cálculo do coeficiente Alpha de Cronbach e da correlação item-total de cada item para cada subescala resultante da Análise fatorial exploratória. A comparação dos fatores de motivação de visita às quintas foi feita por recurso ao teste ANOVA em ordens de Friedman.

Considerando os domínios de motivação identificados na Análise fatorial exploratória foi seguidamente realizada uma análise de Clusters para identificar grupos de enoturistas com motivações semelhantes. Realizouse a comparação entre os participantes considerados na análise e os participantes excluídos assenta no teste de independência do qui-quadrado para variáveis qualitativas e no teste de Kruskall-Wallis quando a análise envolvia uma variável quantitativa. É ainda utilizado o teste de Bonferroni para comparações múltiplas. De seguida utiliza-se a análise de clusters hierárquica pelo método de Ward e com recurso à Distância Euclidiana Quadrática como a distância ou medida de afastamento entre casos. Pela análise dos coeficientes de aglomeração e do dendrograma toma-se a decisão relativamente ao número de clusters. Após a análise hierárquica, procede-se à análise $K$-means para estabelecer a solução final dos clusters. $\mathrm{Na}$ técnica $K$-means analisam-se modelos para diferentes números de clusters. O modelo de clusters mais apropriado é selecionado com base na interpretação e distribuição dos clusters. Confirmando-se o número de agrupamentos, observa-se a tabela Anova, com o propósito de verificar 
em que medida as variáveis em estudo contribuem para a formação dos clusters. A classificação dos clusters finais e sua interpretação assenta, mais uma vez, no teste Kruskall Wallis e em comparações múltiplas de médias de ordens. A distribuição das variáveis demográficas e não demográficas entre os clusters é comparada através do teste do Qui-quadrado e/ou do teste de Bonferroni para comparações múltiplas. Para cada cluster as variáveis são sumariadas com base em estatísticas descritivas.

\section{RESULTADOS E DISCUSSÃO}

\section{FATORES DE MOTIVAÇÃO DOS ENOTURISTAS}

A análise fatorial exploratória que se realizou no sentido de obter uma estrutura de itens motivacionais mais simples do que as iniciais indicou que as variáveis de motivação mostravam-se correlacionadas de modo a poder-se aplicar o modelo fatorial (através da estatística de KMO e do teste de esfericidade). Usou-se a regra do valor próprio para reter os fatores com valores superiores a 1 . Cinco fatores revelaram-se nesta situação, permitindo captar 62,4\% da variância total desses itens (Quadro 1 ). Os fatores foram designados por: lazer (por incluir os itens associados a distração, relaxamento, entretenimento e atividades singulares e agradáveis - explicam 25,99\% da variância); identidade com o local (por incluir os itens com sensação de pertença e ligação genética e cultural - explicam 14,28\% da variância); interesse pelo mundo do vinho (o mundo do vinho e a aprendizagem são um dos motivos que leva a visitar a quinta - explicam 9,8\% da variância); características históricas e físicas do lugar (relaciona a visita com aspetos fiscos e culturais do local - explicam 6,94\% da variância); e acaso (a visita surgiu numa oportunidade não programada no contexto da viagem - explicam 5,78\% da variância).

Quadro 1 - Principais resultados da análise fatorial exploratória

\begin{tabular}{cccccc}
\hline \multicolumn{5}{c}{ Fatores } \\
\hline Itens & 1 & 2 & 3 & 4 & 5 \\
\hline Por que quero algum entretenimento & $\mathbf{0 , 8 4 5}$ & 0,074 & 0,118 & $-0,009$ & 0,128 \\
Por que quero relaxar & $\mathbf{0 , 6 4 9}$ & 0,115 & 0,113 & 0,102 & 0,095
\end{tabular}


ISSN: 1983-7151

Por que não tenho que pagar entrada ou os preços são agradáveis

Para passar o dia fora

0,565

0,280

$-0,280$

0,038

0,340

Para ter uma nova experiência, diferente e única

0,268

$-0,142$

0,144

0,155

Por que tenho a sensação de pertencer a

este lugar
Por que os meus antepassados estão ligados

0,443

0,437

0,206 0,095

ao mundo do vinho

0,115

0,698

0,100

0,041

0,050

0,140

0,653

$-0,120$

0,008

0,140

Por que quero sentir-me emocionalmente implicado

0,209

0,579

0,346

0,164

$-0,034$

Por que faz parte do nosso património e herança cultural

0,023

0,515

0,067

0,442

$-0,097$

Por que sinto que devo visitar este lugar

Por que quero aprender algo sobre o

mundo do vinho, desperta-me curiosidade

0,147

0,407

0,359

0,241

0,164

Por que me interessa especialmente o mundo do vinho

$-0,013$

0,040

0,710

0,280

0,007

\begin{tabular}{c} 
Por que me interessa especialmente 0 \\
mundo do vinho \\
Pelo contexto histórico da região \\
Pela natureza física do lugar \\
Por que nas minhas viagens incluo sempre \\
visitas culturais \\
\hline $\begin{array}{c}\text { Por que estava incluído no meu programa } \\
\text { da viagem }\end{array}$
\end{tabular}

Por que fica no caminho para outro lugar

$-0,055$

0,135

0,706

0,089

0,024

0,015

0,203

0,148

0,141

0,761

0,083

0,059

0,111

0,161

0,715

0,054

0,151

$-0,016$

0,339

0,443

0,107

Por que é um lugar famoso

0,351

$-0,026$

0,107

0,060

0,561

Valores próprios

0,216

0,237

$-0,167$

0,026

0,422

Alfa de Cronbach

25,99
4,68
0,769

0,209

0,195

0,200

0,300

14,28

9,49

6,94

5,78

2,57

1,71

1,25

1,04

0,753

0,740

0,714

0,457

A Figura 1 identifica, por ordem de importância, os motivos que levaram os enoturistas a visitarem a quinta. Barras de erro representam amplitude interquartil. Letras diferentes indicam diferenças significativas entre os fatores de motivação com base nas comparações múltiplas.

Figura 1: Pontuações medianas dos motivos que levaram os enoturistas a visitar a adega/quinta/cave

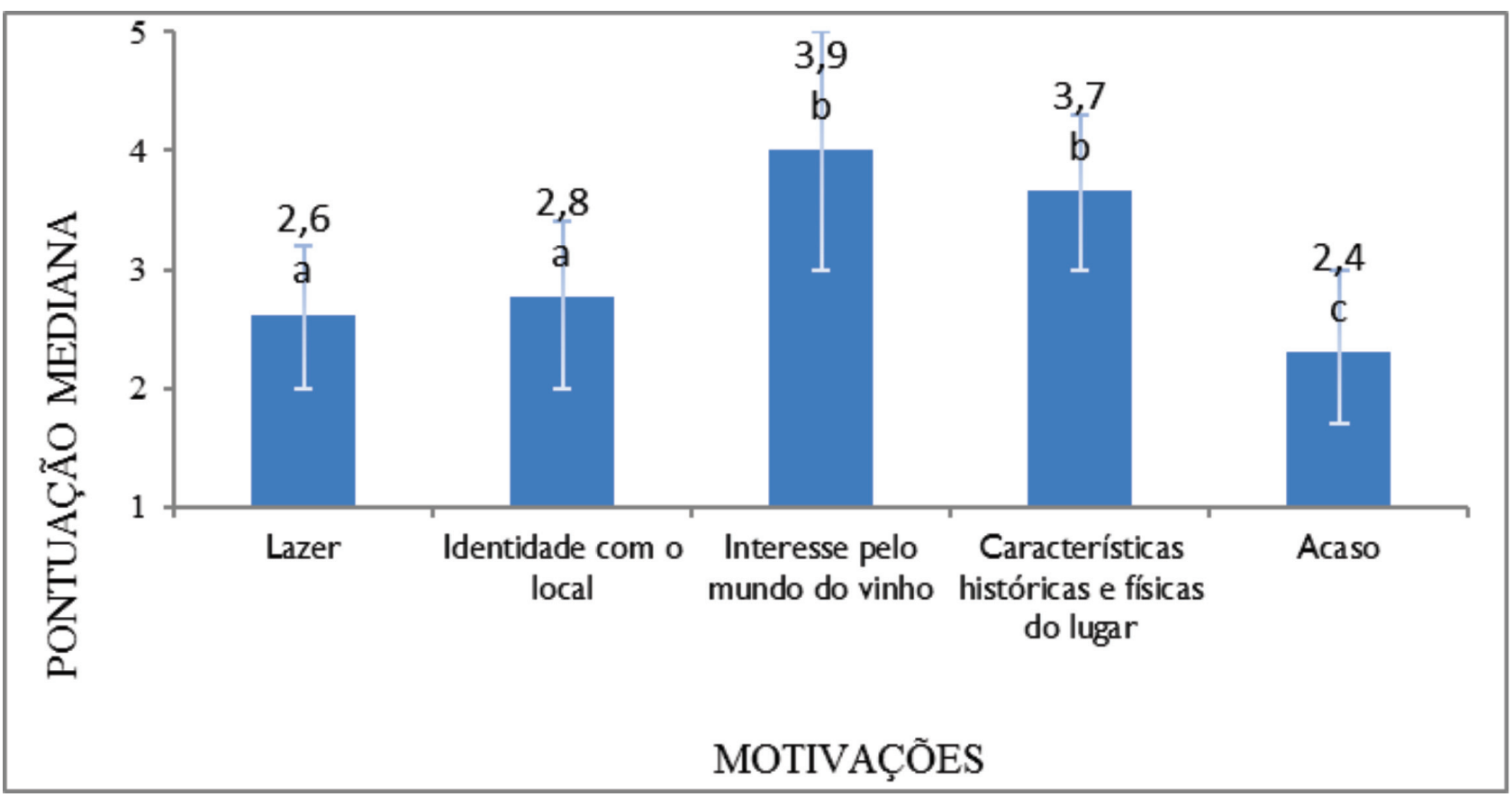




\section{SEGMENTAÇÃO DOS ENOTURISTAS}

Considerando os domínios de motivação identificados na Análise fatorial exploratória, foi realizada uma análise de clusters para identificar grupos de enoturistas com motivações semelhantes. Um dendograma de semelhança foi realizado a partir dos dados em estudo. Foi considerado optar pela solução de 4 clusters, já que representaria melhor os nossos dados, porque dela emergiu um número mais equilibrado de sujeitos e os perfis de agrupamento foram mais interpretáveis no contexto teórico. A Figura 2 apresenta a mediana de cada variável em cada um dos grupos criados.

Figura 2: Mediana dos Z-scores obtidos na AFE correspondentes aos grupos obtidos pela análise de clusters

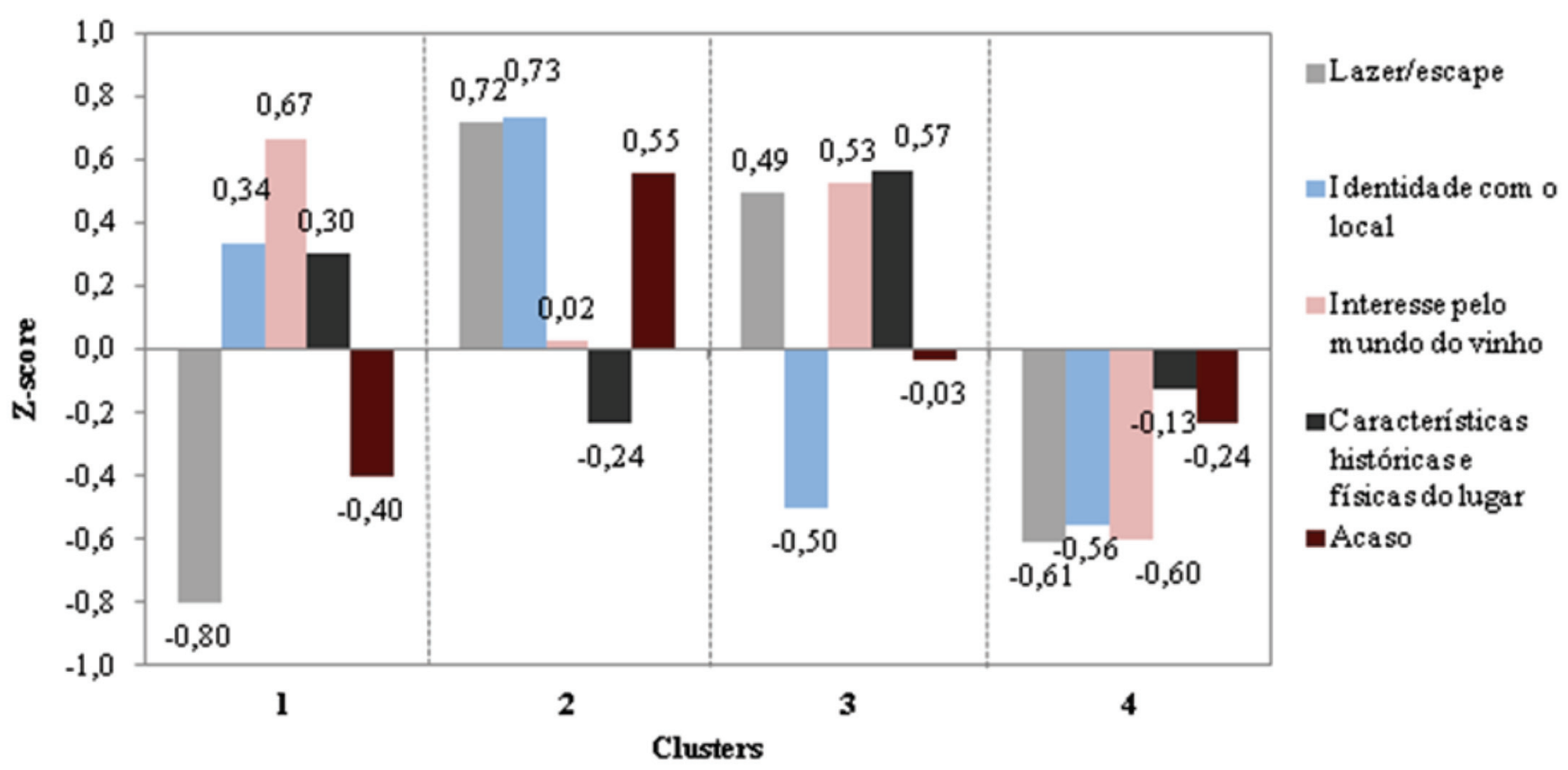

O Quadro 2 apresenta as características demográficas dos participantes pelos 4 clusters, evidenciando diferenças significativas relativamente à idade, ao estado civil, à nacionalidade e ao rendimento.

Quadro 2 - Distribuição das variáveis sociodemográficas pelos quatro clusters 


\begin{tabular}{|c|c|c|c|c|c|c|}
\hline & & Cluster 1 & Cluster 2 & Cluster 3 & Cluster 4 & \\
\hline & & & $\mathrm{N}(9$ & & & Valor $p$ \\
\hline \multirow{2}{*}{ Sexo } & Masculino & $44(52,4)$ & $43(54,4)$ & $35(52,2)$ & $62(66,7)$ & \multirow{2}{*}{0,164} \\
\hline & Feminino & $40(47,6)$ & $36(45,6)$ & $32(47,8)$ & $31(33,3)$ & \\
\hline \multirow{5}{*}{ Idade } & 18 a 25 anos & $3(3,6)^{a, b}$ & $10(12,7)^{\mathrm{b}}$ & $2(3,0)^{a, b}$ & $1(1,1)^{\mathrm{a}}$ & \multirow{5}{*}{0,013} \\
\hline & 26 a 35 anos & $26(31,0)^{a}$ & $17(21,5)^{\mathrm{a}}$ & $11(16,4)^{a}$ & $20(21,5)^{a}$ & \\
\hline & 36 a 45 anos & $20(23,8)^{a}$ & $15(19,0)^{\mathrm{a}}$ & $17(25,4)^{a}$ & $14(15,1)^{\mathrm{a}}$ & \\
\hline & 46 a 55 anos & $14(16,7)^{\mathrm{a}}$ & $14(17,7)^{\mathrm{a}}$ & $19(28,4)^{a}$ & $24(25,8)^{a}$ & \\
\hline & Mais de 56 anos & $21(25,0)^{a}$ & $23(29,1)^{a}$ & $18(26,9)^{\mathrm{a}}$ & $34(36,6)^{a}$ & \\
\hline \multirow{3}{*}{ Estado civil } & Solteiro & $14(16,7)^{a, b}$ & $25(31,6)^{b}$ & $13(19,4)^{a, b}$ & $10(10,8)^{a}$ & \multirow{3}{*}{0,017} \\
\hline & Casado & $60(71,4)^{a, b}$ & $50(63,3)^{b}$ & $47(70,1)^{a, b}$ & $77(82,8)^{\mathrm{a}}$ & \\
\hline & $\begin{array}{c}\text { Separado/ } \\
\text { divorciado/viúvo }\end{array}$ & $10(11,9)^{a}$ & $4(5,1)^{a}$ & $7(10,4)^{a}$ & $6(6,5)^{\mathrm{a}}$ & \\
\hline \multirow[b]{2}{*}{ Nacionalidade } & Português & $69(82,1)^{a, b}$ & $73(92,4)^{b}$ & $48(71,6)^{a}$ & $65(69,9)^{a}$ & \multirow[b]{2}{*}{0,001} \\
\hline & Estrangeiro & $15(17,9)^{a, b}$ & $6(7,6)^{b}$ & $19(28,4)^{a}$ & $28(30,1)^{a}$ & \\
\hline \multirow{3}{*}{$\begin{array}{l}\text { Formação } \\
\text { académica } \\
\text { - } 3 \text { níveis }\end{array}$} & $\begin{array}{l}\text { Ensino básico/ } \\
\text { secundário }\end{array}$ & $16(19,0)$ & $18(22,8)$ & $9(13,4)$ & $24(25,8)$ & \multirow{3}{*}{0,181} \\
\hline & $\begin{array}{l}\text { Bacharelato/ } \\
\text { licenciatura }\end{array}$ & $46(54,8)$ & $43(54,4)$ & $31(46,3)$ & $41(44,1)$ & \\
\hline & $\begin{array}{c}\text { Mestrado/ } \\
\text { doutoramento }\end{array}$ & $22(26,2)$ & $18(22,8)$ & $27(40,3)$ & $28(30,1)$ & \\
\hline \multirow[t]{3}{*}{ Rendimento } & Menos de $1250 €$ & $31(36,9)^{a, b}$ & $35(44,3)^{b}$ & $16(23,9)^{a, b}$ & $21(22,6)^{a}$ & 0,010 \\
\hline & $1251-2500 €$ & $31(36,9)^{a}$ & $31(39,2)^{a}$ & $26(38,8)^{a}$ & $37(39,8)^{a}$ & \\
\hline & $>2500$ & $\begin{array}{l}2 \quad 2 \\
(26,2)^{a, b}\end{array}$ & $\begin{array}{l}1 \\
(16,5)^{b}\end{array}$ & $\begin{array}{l}2 \quad 5 \\
(37,3)^{a}\end{array}$ & $\begin{array}{l}3 \quad 5 \\
(37,6)^{a}\end{array}$ & \\
\hline
\end{tabular}

a, b - letras diferentes representam diferenças significativas entre os grupos

Da investigação efetuada resultou a denominação e a caracterização dos diferentes grupos de turistas. Assim os quatro clusters obtidos podem ser descritos da seguinte forma:

Cluster 1: O turista apaixonado pelo vinho. Este cluster constitui $26 \%$ da amostra. Mais de $40 \%$ dos elementos que integram este grupo possuem idade superior a 46 anos. São maioritariamente casados e mais de $80 \%$ possui bacharelato/licenciatura ou mestrado/doutoramento. Neste cluster, 26,2\% dos indivíduos possui rendimento superior a $2500 €$. Mais de $70 \%$ dos visitantes das adegas/ quintas/caves consideram-se muito satisfeitos com a visita realizada e deslocaram-se a esse local por iniciativa própria. São indivíduos em que o fator lazer é pouco importante para visitar uma adega/ quinta e que têm muito interesse pelo mundo dos vinhos, sendo o cluster com maior percentagem de indivíduos que são apreciadores/ 
consumidores de vinho (95,2\%). Mais de $80 \%$ considera-se como um grau de conhecimento médio, bom ou muito bom sobre vinhos (mais de $50 \%$ considera-se um apreciador de nível médio de vinho, 20,2\% com um conhecimento de nível bom e 7,1\% de nível muito bom), demonstrando interesse moderadamente elevado com a identidade com o local e com as características históricas e físicas do lugar). Tal como é verificável na Figura 2, este cluster demonstra interesse pelo mundo dos vinhos. Este aspeto, associado ao facto de este cluster ser constituído por grandes apreciadores/consumidores de vinho, além de possuírem um elevado grau de conhecimento sobre vinhos, levou a denominar este cluster como o dos "turistas apaixonados pelo vinho".

Cluster 2: 0 turista com curiosidade pelo vinho. É um cluster que constitui $24,5 \%$ da amostra, sendo constituído por um número considerável de indivíduos com idade igual ou inferior a 25 anos, mas mesmo assim mais de $79 \%$ dos indivíduos possuem uma idade superior a 26 anos. É o cluster que maior percentagem tem de indivíduos solteiros, assim como indivíduos de nacionalidade portuguesa. Dos 4 clusters propostos este é o que possui menor percentagem de indivíduos apreciadores/consumidores de vinho $(83,5 \%)$, apesar de quase $80 \%$ dos indivíduos que constituem este cluster consideram-se com um conhecimento sobre vinhos de médio a elevado e a visita à quinta em questão foi através de uma entidade/empresa (48,7\%). Quase $80 \%$ possui habilitação igual ou superior a bacharelato/licenciatura e poucos indivíduos possuem um rendimento mensal superior a $2500 €(16,5 \%)$. Como se pode observar pela Figura 2, são indivíduos que possuem pouco interesse nas características físicas e históricas do local, assim como pelo mundo do vinho. No entanto, possuem elevado interesse no lazer/ escape e identidade com o local e, casualmente, visitaram a quinta, o que levou a apelidá-los de "turistas curiosos".

Cluster 3: 0 turista interessado pelo vinho. Este cluster constitui $20,1 \%$ da amostra e é o que maior percentagem apresenta de indivíduos do sexo feminino, com $47,8 \%$, juntamente com o grupo respeitante ao cluster 1 com 47,6\%. É um cluster com uma percentagem elevada de indivíduos com mais de 46 anos (55,3\%), possuindo $92,5 \%$ de indivíduos que se consideram apreciadores/ consumidores de vinho. O cluster é constituído por indivíduos que se consideram com um grau de conhecimento sobre vinhos muito bom, sendo dos 4 clusters obtidos, aquele que apresenta valores mais elevados para este item $(7,5 \%)$ e é o que não tem qualquer indivíduo que se considera com conhecimentos nulos sobre vinho. É o cluster com maior percentagem de indivíduos com um nível de satisfação relativamente à visita efetuada dentro do item de muito 
satisfeito (79,4\%). Este cluster possui a maior percentagem de indivíduos que auferem de um rendimento mensal superior a 2500 euros (37,6\%), assim como entre 1251 e $2500 €(39,8 \%$ ). Mais de $40 \%$ dos indivíduos possui mestrado ou doutoramento e viajaram por iniciativa própria. É um cluster formado por indivíduos com muito interesse no lazer/escape e nas características históricas e físicas do lugar, identificando-se no entanto pouco com o lugar visitado. Possui muito interesse pelo mundo do vinho, ainda que menos interesse que o cluster constituído pelos "turistas apaixonados pelo vinho" (Figura 2). As diferentes características levaram a designar este grupo como o grupo constituído pelo "turista interessado pelo vinho".

Cluster 4: 0 turista indiferente. Este cluster constitui $28,8 \%$ da amostra e é o que maior percentagem apresenta de indivíduos do sexo masculino (66,7\%). O mesmo se verifica relativamente à idade, já que é o cluster com maior percentagem de indivíduos na faixa etária com mais de 56 anos (36,6\%). Dos 4 clusters é aquele que apresenta maior valor percentual de indivíduos com habilitação equivalente ao ensino básico/secundário (25,8\%). Quanto questionados sobre se se consideram apreciadores/consumidores de vinho, 93,8\% dos indivíduos deste auto incluem-se neste item. Apesar de ser o grupo que possui percentualmente maior quantidade de indivíduos que se consideram com um grau de conhecimento bom sobre vinho (32,3\%), é simultaneamente aquele que apresenta a menor percentagem de indivíduos com um conhecimento médio ou muito bom (36,6\% e $5,4 \%$ respetivamente). Apenas $53,2 \%$ dos indivíduos se consideram muito satisfeitos com a visita, ocupando os valores mais baixos para este item dos quatro clusters considerados. De acordo com a Figura 2 , este grupo é constituído por indivíduos com pouco interesse no lazer/escape e nas características históricas e físicas do lugar, identificando-se pouco com este, além de serem pouco interessados pelo mundo do vinho, o que levou a identificar este cluster com "o turista indiferente".

\section{CONSIDERAÇÕES FINAIS}

Os resultados obtidos possibilitaram compreender o perfil do enoturista em Portugal, caracterizando-se este como predominantemente do género masculino (59.5\%), com idade compreendida entre os 18 e os 45 anos (57.4\%), casado ou vivendo em união de fato (72.5\%), de nacionalidade portuguesa (76.6\%), habilitado com bacharelato ou licenciatura, com um salário mensal entre $1251 €$ e $3500 €$ e que trabalha por conta de outrem. 
A análise factorial exploratória permitiu identificar 5 domínios de motivação que explicavam $62,49 \%$ da variância total e designados: Lazer, Identidade com o local, Interesse pelo Mundo do vinho, Características históricas e físicas do lugar e Acaso. Com base nestes domínios de motivação foi possível identificar 4 segmentos de enoturistas que se deslocam às caves/quintas/adegas em Portugal: o grupo designado turista apaixonado pelo vinho, o grupo designado turista com curiosidade pelo vinho, o grupo turista interessado pelo vinho e, por último, o grupo turista indiferente.

Sendo Portugal um país onde o desenvolvimento do enoturismo se encontra numa fase emergente, tornam-se importantes: a identificação dos diferentes grupos de enoturistas, os seus gostos, os desejos e as preferências. Os resultados obtidos neste trabalho muito poderão contribuir para a compreensão e conhecimento do enoturista. Através da disponibilidade destes resultados, as empresas vinícolas têm agora acesso a uma compreensão mais profunda de todos os aspetos relativos ao enoturista, que podem ter um impacto favorável sobre o desenvolvimento do enoturismo. Os resultados poderão ser úteis não apenas para os gestores das empresas vitivinícolas mas, igualmente, para as autoridades locais e regionais responsáveis pela aplicação de medidas de gestão relacionadas com o turismo.

Com base nos resultados obtidos, os gestores de adegas poderão implementar estratégias de marketing e de comunicação adequadas a cada grupo, de modo a manterem-se competitivos na indústria do turismo. Por exemplo, os grupos constituídos pelos turistas apaixonados pelo vinho e pelos turistas com interesse pelo vinho, são grupos com indivíduos atraídos pelo mundo dos vinhos. As estratégias adotadas pelos gestores das quintas têm que ser no sentido de permitir um aumento do conhecimento do mundo dos vinhos por parte de quem as visita e promover a oferta de um conjunto de atividades relacionadas com o vinho. Já, por exemplo, aos indivíduos que fazem parte do grupo de turistas com curiosidade pelo vinho, poderão ser oferecidas atividades alternativas complementares não relacionadas diretamente com o vinho, mas produzindo valor acrescentado à região. São exemplos os restaurantes locais, alojamentos, lojas de artesanato, etc., já que os indivíduos em questão, além de 
possuírem um poder de compra elevado, são também indivíduos que possuem interesse no lazer/escape e identidade com o local.

As adegas deverão, igualmente, instruir adequadamente os seus empregados, no sentido de garantir que eles promovam o envolvimento turístico que os diferentes segmentos de consumidores idealizam. $O$ staff da adega deve ser capaz de interagir e de moldar o seu discurso, no sentido de manter o cliente em questão interessado durante todo o processo de experiência na adega. Um visitante experiente vai preferir alguém que Ihe explique o produto vinho, com um conhecimento e experiência profunda sobre o vinho.

Num estudo desta natureza, é sempre importante que se apontem as limitações encontradas e que poderão dar linhas de orientação para futuros trabalhos sobre o tema. À semelhança de outras investigações, obteve-se como resultado um estudo que não se pretende encerrado, mas aberto à possibilidade de ser melhorado, nomeadamente com a aplicação de novas técnicas e metodologias de análise. Pela sua dimensão holística, sendo um trabalho de caráter pioneiro, tem a responsabilidade acrescida de que, a partir dele, futuras investigações possam ter lugar e confirmar ou não as conclusões obtidas.

Algumas limitações foram sendo anotadas ao longo da realização deste trabalho. No estudo empírico, foram indicados pelos responsáveis das diferentes rotas do vinho cerca de 100 aderentes como sendo os aderentes que maior representatividade teriam na recepção da quantidade de turistas às suas instalações. Desejável, seria aplicar a possibilidade de resposta ao questionário aos visitantes de todos os aderentes de cada rota, atingindose assim um maior número de respostas e muito provavelmente uma maior diversidade de tipos de turistas de vinho. Daí, resultaria a possibilidade de uma generalização dos resultados obtidos, para uma dimensão nacional mais alargada. Aderiram a responder ao questionário apenas os indivíduos que acederam ao convite para fornecerem o seu endereço eletrónico, para receberem o link de acesso para a resposta ao inquérito. A metodologia usada, derivada de condicionantes económicas e temporais, pode ser considerada como limitativa, já que se baseou numa amostragem por voluntários, logo um tipo de amostragem não probabilística que impossibilita a generalização 
dos resultados. Mais enriquecedor para o estudo seria que se verificasse a possibilidade de auscultar uma amostra mais próxima da população alvo, mas isso carecia de mais informação sobre essa população, inexistente à data do estudo. Assim, seria permitido que todos os elementos da população tivessem probabilidade conhecida e diferente de zero, de pertencer à amostra, algo que não se verificou. Contudo, dados os condicionalismos apresentados, acredita-se que a opção pelo modelo de aplicação do inquérito on-line foi a mais razoável e exequível para a concretização do estudo.

Dada a evolução rápida e contínua da sociedade e dos condicionantes socioeconómicos dos indivíduos, ao mesmo tempo que vão surgindo outras variáveis que influenciam a deslocação de um turista a uma região produtora de vinhos e às suas adegas, sugere-se a realização de futuras investigações, de modo a pesquisar a existência de outros fatores que possam influenciar a motivação para a deslocação de um turista a uma adega. Assim, a realização deste estudo em espaços intervalados e periódicos de alguns anos faria todo o sentido.

Tem-se verificado que o esforço despendido para desenvolver e divulgar um determinado vinho se repercute na probabilidade de desenvolver a indústria do vinho existente nessa região. A fama de determinada região tem uma influência no turista, no sentido de o levar a visitar as áreas de produção em causa, passando aquele destino, deste modo, a ser considerado pelo turista como um destino de eleição a visitar. À semelhança de outros estudos realizados fora de Portugal, seria interessante a realização de estudos similares no nosso território, para investigar a possível relação entre o vinho preferencialmente consumido pelo enoturista e as motivações para a visitação à região em causa. O facto de o estudo ter sido desenvolvido com o intuito de estudar o perfil e obter os diferentes segmentos dos turistas de vinho poderá fazer com que estudos semelhantes sejam aplicados a outras áreas do conhecimento, com o ajustamento prévio dos indicadores.

\section{REFERÊNCIAS}

Ajzen, I., \& Fishbein, M. (1980) Understanding attitudes and predicting behavior. Englewood Cliffs, NJ: Prentice-Hall. 
Alebaki, M. \& Iakovodou, O. (2010) Segmenting the Greek Wine Tourism Market using a Motivational Approach. New Medit, 9(4), 31-40.

Baloglu, S. (2001) Image Variations of Turkey by Familiarity Index: Informational and Experiential Dimensions. Tourism Management, 22 (2), 127-133.

Barber, N., Taylor, D. C. \& Dodd, T. (2009) The Importance of Wine Bottle Closures in Retail Purchase Decisions of Consumers. Journal of Hospitality Marketing \& Management, 18 (6), 597-614.

Brown, G. \& Getz, D. (2005) Linking wine preferences to the choice of wine tourism destinations. Journal of Travel Research, 43 (3), 266-276.

Brown, G., Havitz, M. E. \& Getz, D. (2006) Relationship between wine involvement and wine related travel. Journal of Travel \& Tourism Marketing, 2 (1), 31-46.

Bruwer, J., Li, E. \& Reid, M. (2002) Segmentation of the Australian Wine Market Using a Wine-Related Lifestyle Approach. Journal of Wine Research, 13 (3), 217-242.

Charters, S. \& Ali-Knight, J. (2002) Who is the wine tourist? Tourism Management Journal, 23 (3), 311-319.

Charters, S. \& Ali-Knight, J. (2006) Survey timing and visitor perceptions of cellar door quality, in Carlsen, J. \& Charters, S., Global Wine Tourism: Research, Management and Marketing, CAB International, Cambridge, USA, 161-176.

Chen, H. \& Sasias, M. (2014) Tourist Segmentation in Taiwan's Wineries: a Cultural Perspective. Social Behavior and Personality, 42 (2), 223-236.

Corigliano, M. A. (1996) Caratteristiche della Domanda Strategie di Offerta e Aspetti Territoriali e Ambientali, Franco Angeli, Milano.

Dawson, H., Jacobs, H. \& Wade, R. I. (2011) Wine tourism: Winery visitation in the wine appellations of Ontario. Journal of Vacation Marketing, 17 (3), 237-246.

Dodd, T. \& Bigotte, V. (1997) Perceptual differences among visitor groups to wineries. Journal of Travel Research, 35 (3), 46-51.

Dodd, T. (1995) Opportunities and pitfalls of tourism in a developing wine industry. International Journal of Wine Marketing, 7 (1), 5-16.

Dodd, T. (1999) Attracting repeat customers to wineries. International Journal of Wine Marketing, 11 (2), 18-26.

Favero, R. I. \& Rotta, A. J. (2007) Enoturismo en la Región de la uva y el vino: Brasil. Estudios e Perspectivas en Turismo, 16 (2), 133-149. 
Folwell, R. J. \& Grassel, M. A. (1995) How tasting rooms can help sell wine. In University of Arizona (eds.), Department of Agricultural and Resource Economics, Direct Farm Marketing and Tourism Handbook, Arizona, The University of Arizona, 11-15.

Galloway, G., Mitchell, R., Getz, D., Crouch, G. \& Ong, B. (2008) Sensation seeking and the prediction of attitudes and behaviours of wine tourists, Tourism Management, 29 (5), 960-966.

Getz, D, (2000) Explore Wine Tourism, Management, Development \& Destinations, Library of Congress Cataloging, USA.

Getz, D. \& Brown, G. (2006) Critical sucess factors for wine tourism regions: a demand Analysis. Tourism Management, 27 (1), p. 146-158.

Ghiglione, R \& Matalon, B. (2001) O Inquérito, Teoria e Prática, Oeiras, Celta Editora, 4. ${ }^{\text {a }}$ edição, Oeiras.

Goldberg, M. A. \& Murdy, J. (2006) Wine tourism after the direct shipment revolution: implications and a proposed methodological framework. International Business and Economics Research Journal, 5 (2), 1-10.

Hall, C. M. (1996) Wine tourism in New Zealand. In G. Kearsley (Eds.) Proceedings of Tourism Down Under II: A Tourism Research Conference, Dunedin: Centre for Tourism, University of Otago.

Hall, C. M. \& Macionis, N. (1998) Wine tourism in Australia and New Zealand, in Butler, R., Hall, C. M. and Jenkins, J. (eds), Tourism and Recreation in Rural Areas, John Wiley \& Sons, Chichester, 197-224.

Hall, C. M., Johnson, G., Cambourne, B., Macionis, N., Mitchell, R. \& Sharples, L. (2002a) Wine tourist: an introduction, in C. M. Hall, M, L. Sharples, B. Cambourne, \& N. Macionis (Eds.), Wine Tourism Around the World: Development, Management and Markets. Oxford: ButterworthHeinemann, 1-23.

Hall, M., Longo, A. M., Mitchell, R. \& Johnson, G. (2002b) Wine Tourism in New Zealand, in C. M. Hall, M, L. Sharples, B. Cambourne \& N. Macionis (Eds.), Wine Tourism Around the World: Development, Management and Markets. Oxford: Butterworth-Heinemann, 150-174.

Hill, M. M. \& Hill, A. (2005) Investigação por Questionário, Lisboa, Edições Sílabo, 2. ${ }^{\text {a }}$ edição revista e aumentada.

Iglesias, M.P. \& Navarro, M.M. (2014) Desarrolo del enoturismo desde la perspectiva de las bodegas familiares, Cuadernos de Turismo, 34, 233-249 
Jang, S. C., Morrison, A. M. \& O'Leary, J. T. (2002) Benefit segmentation of Japanese pleasure travellers to the USA and Canada: selecting target markets based on the profitability and risk of individual market segments. Tourism Management, 23 (4), 367-378.

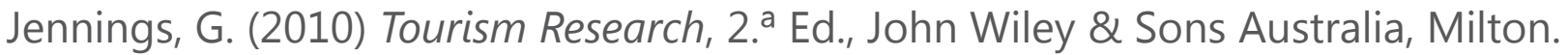

Johnson, R. \& Bruwer, J. (2007) Regional brand image and perceived wine quality: the consumer perspective. International Journal of Wine Business Research, 19 (4), p.276-297.

Kerstetter, D.\& Cho, M. (2004) Prior knowledge, credibility and information search, Annals of Tourism Research, 31 (4), 961-985.

Lavandoski, J., Vargas-Sánchez, A., Pinto, P. \& Silva, J. A. (2016) Causes and effects of wine tourism development in organizational context: The case of Alentejo, Portugal. Tourism and Hospitality Research. doi:10.1177/1467358416634159.

Marzo-Navarro, M. \& Pedraja-Iglesias, M. (2009a) Wine tourism development from the perspective of the potencial tourist in Spain, International Journal of Contemporany Hospitality, 21 (7), p. 816-835.

Marzo-Navarro, M. \& Pedraja-Iglesias, M. (2009b) Profile of a wine tourist and the correspondence between destination and prefered wine. A study in Aragon, Spain. Journal of Travel \& Tourism Marketing, 26 (7), 670-687.

Marzo-Navarro, M. \& Pedraja-Iglesias, M. (2010) Are there different profiles of wine tourists? An initial approach in Spain. International Journal of Wine Business Research, 2 (4), 349-361.

Mitchell, R. \& Hall, C. M. (2003) Seasonality in New Zealand winery visitation: An issue of demand and supply. Journal of Travel and Tourism Marketing, 14 (3/4), 155-173.

Mitchell, R. \& Hall, C. M. (2006) Wine tourism research: the state of play. Tourism Review International, 9 (4), 307-332.

Mitchell, R., Hall, C. M. \& McIntosh, A. (2002) Wine tourism and consumer behaviour, in C. M. Hall, M, L. Sharples, B. Cambourne \& N. Macionis (Eds.), Wine Tourism Around the World: Development, Management and Markets. Oxford: Butterworth-Heinemann, 115-135.

Morton, S. \& Houghton, M. (2008) The message of a Wine Brand, Conference Competition in Tourism: Business and Destination Perspectives, University of Applied Science Helsinki, April 23-25, p. 446-455. Disponivel em: http://myy.haaga-helia.fi/ tk/TTRA/ ProceedingsTTRA2008.pdf (acedido em 4 de julho de 2010.2. 
O’Neill, M. \& Charters, S. (2006) Survey Timing and Visitor Perceptions of Cellar Door Quality, in Carlsen, J. \& Charters, S., Global Wine Tourism: Research, Management and Marketing, CAB International, Cambridge, USA, 161-176.

Oliveira, A. P. (2002) Turismo e Desenvolvimento, Planejamento e Organização S. Paulo, $4 .^{a}$ edição, Editora Atlas S.A.

Pastor, E. L. V. (2006) El turismo del vino. Otra experiencia de ocio. Bilbao: Estudios de Ocio, Universidad de Deusto, Bilbau.

Pike, S. (2002) Destination image analysis-a review of 142 papers from 1973 to 2000. Tourism Management, 23 (5), 541-549.

Roberts, L. \& Sparks, B. (2006) Enhancing the Wine Tourism Experience: the Customer's Viewpoint, in Carlsen, J. \& Charters, S., Global Wine Tourism: Research, Management and Marketing, CAB International, Cambridge, USA, 47-55.

Simões, O. (2008) Enoturismo em Portugal: as Rotas de Vinho. Revista Pasos, Revista de Turismo e Património Cultural, Instituto Universitário de Ciências Políticas e Sociais, Universidad de La Laguna, España, 6 (2), 269-280.

Sparks, B. (2007) Planning a wine tourism vacation? Factors that help to predict tourist behavioural intentions, Tourism Managment, 28 (5), p. 1180 -1192.

Stoddard \& Evans (2011) Discover North Carolina Wines: A Winery Visitor Marketing Profile Study. Disponível em: http://www.ncagr.gov/markets/Portals/10/Documents/ WineryVisitorProfileStudy2010.pdf (acedido em 12 de setembro de 2013).

Tassiopoulos, D. \& Haydam, N. (2006) Wine Tourist in South Africa: a demand-side Study, in Carlsen, J. \& Charters, S., Global Wine Tourism: Research, Management and Marketing, CAB International, Cambridge, USA, 141-152.

Tassiopoulos, D., Nuntsu, N. \& Haydam, N. (2004) Wine Tourists in South Africa: A Demographic and Psychographic Study, Journal of Wine Research, 15 (1), 51-63.

Taylor, J. (2001) Authenticity and sincerity in tourism. Annals of Tourism Research, $28(1), 7-26$.

Tonini, H. (2007) Estado e turismo: políticas públicas e enoturismo no Vale dos Vinhedos. Dissertação (Mestrado em Turismo). Universidade de Caxias do Sul. Caxias do Sul. Disponível em: http://tede.ucs.br/tde_arquivos/3/TDE-2008-02-27T070057Z-174/Publico/ Dissertacao\%20Hernanda\%20Tonini.pdf (acedido em 3 de janeiro de 2010). 
Torre, G. M., Ferreira, A. M., \& Lopez-Guzman, T. (2008) O Enoturismo: Nova Alternativa ao Turismo Tradicional. Um estudo de caso. Revista Turismo \& Desenvolvimento, 10, 85-95.

Treloar, P., Hall, C. M. \& Mitchell, R. D. (2004) Wine Tourism and the generation Y market: any possibilities? Paper presented at the CAUTHE 2004 conference. Brisbane, Queensland, Australia: 10-13 February 2004). Disponível em: http://otago.ourarchive.ac.nz/bitstream/ handle/10523/687/Treloar\%20et\%20al.\%20CAUTHE\%20full.pdf?sequence=2 (acedido em 23 de setembro de 2013).

Wang, N. (1999) Rethinking authenticity in tourism experiences. Annals of Tourism Research, 26 (2), 349-370.

Williams, A. \& Young, I. (1999) Wine tourists: white wine casks or bottled reds? Paper presented at the Second Australian Wine Tourism Conference, Rutherglen, August, 1999.

Williams, P. \& Kelly, J. (2001) Cultural wine tourists: product development considerations for British Columbia's resident wine tourism market. International Journal of Wine Marketing, 13 (3), 59-77.

Zamora, J. \& Barril, M. E. (2007) Turismo y Vino: Un estudio formative sobre la evolución de las rutas del vino en Chile. Estudios y Perspectivas en Turismo, 16, (2), 173-194. 